\title{
Upregulation of EPS8L3 is associated with tumorigenesis and poor prognosis in patients with liver cancer
}

\author{
PENG LI $^{1 *}$, TING HU ${ }^{2 *}$, HONGSHENG WANG $^{1}$, YING TANG $^{3}$, YUE MA ${ }^{1}$, \\ XIAODONG WANG ${ }^{4}$, YANSONG XU ${ }^{1}$ and GUANGYU CHEN ${ }^{1}$ \\ ${ }^{1}$ Department of Hepatopancreatobiliary Surgery, Affiliated Hospital of Beihua University, Jilin 132001; \\ ${ }^{2}$ Department of Oncology, The First Affiliated Hospital to Changchun University of Chinese Medicine, \\ Changchun, Jilin 130021; ${ }^{3}$ Department of Nursing, Affiliated Hospital of Beihua University, Jilin 132001; \\ ${ }^{4}$ Medical Department, Huailai County Hospital of Traditional Chinese Medicine, Zhangjiakou, Hebei 075400, P.R. China
}

Received August 5, 2018; Accepted May 23, 2019

DOI: $10.3892 / \mathrm{mmr} .2019 .10471$

\begin{abstract}
Epidermal growth factor receptor kinase substrate 8 (EPS8) plays critical roles in a variety of solid tumors. However, the biologic functions and clinical significance of EPS8-like 3 (EPS8L3), an EPS8-related protein, in liver cancer remain unclear. To measure EPS8L3 expression in liver cancer cell lines, reverse transcription-quantitative PCR and western blot analyses were performed. The correlation between 338 patients with liver cancer and various clinicopathological factors obtained from the Oncomine database were evaluated using the $\chi^{2}$ test. Survival of patients with different expression of EPS8L3 was determined using Kaplan-Meier survival analysis with a log rank test, and Cox regression analysis was performed to estimate the prognostic significance of EPS8L3 expression. Additionally, cell proliferation and migration were determined using Cell Counting Kit- 8 and wound healing assays. The results revealed that EPS8L3 expression was significantly upregulated in liver cancer tissues and cell lines $(\mathrm{P}<0.01)$, and that the expression of EPS8L 3 was closely associated with grade $(\mathrm{P}=0.024)$ and mortality $(\mathrm{P}=0.011)$. Furthermore, survival analysis suggested patients with high EPS8L3 expression exhibited shorter survival compared with those with low EPS8L3 expression. Cox regression analysis indicated that EPS8L3 could be regarded as a prognostic biomarker in patients with liver cancer (hazard ratio, 1.58; 95\% confidence interval, 1.085-2.301; $\mathrm{P}=0.017$ ). Additionally, in vitro assays revealed that EPS8L3 depletion significantly inhibited liver cancer cell proliferation and migration, and
\end{abstract}

Correspondence to: Dr Guangyu Chen, Department of Hepatopancreatobiliary Surgery, Affiliated Hospital of Beihua University, 12 Jiefangzhong Road, Jilin 132001, P.R. China

E-mail: cgyahbhu@163.com

*Contributed equally

Key words: epidermal growth factor receptor kinase substrate 8like 3, liver cancer, prognosis, PI3K/AKT pathway reduced the levels of phosphorylated PI3K and AKT in the PI3K/AKT signaling pathway. Collectively, the results of the present study, for the first time to the best of our knowledge, demonstrated that EPS8L3 serves as an oncogene in liver cancer development; therefore, EPS8L3 may be a valuable prognostic predictor for patients with liver cancer.

\section{Introduction}

Liver cancer, including hepatocellular carcinoma and intrahepatic cholangiocarcinoma, is one of the most common malignancies worldwide (1). Additionally, liver cancer is the third leading cause of cancer-associated mortality worldwide, after lung and gastric cancer (1). A variety of aberrant genes and signaling transduction pathways are involved in the occurrence and development of liver cancer, which contribute to a complex pathogenesis (2-4). At present, surgery is the main clinical treatment for liver cancer; however, a lack of early clinical symptoms makes diagnosis difficult $(5,6)$. Additionally, despite advances in treatment, such as liver transplantation and chemotherapeutic interventions, the therapeutic effects are inadequate due to tumor recurrence and metastasis $(7,8)$, meaning patients with the disease have a poor prognosis. Therefore, an in-depth investigation to improve the understanding of the molecular mechanisms underlying liver cancer and to identify accurate markers for the prognosis of liver cancer remains urgent.

Previous studies have found that EPS8 plays an important role in a wide variety of cancers, including oral cancer (9), pancreatic cancer (10), non-small cell lung cancer (11), and head and neck squamous cell carcinomas (12). As such, EPS8 is proposed to be an important target in multiple cancer types (13). EPS8 has pro-tumorigenic potential of in a variety of tumors and specific inhibitors derived from the nuclear localization signal (NLS) sequence are responsive to tumor-associated proteins. Chen et al (14) found that the injection of an EPS8-NLS peptide exerted anti-tumor activity in xenograft tumor models of acute myeloid leukemia, further indicating the pro-tumorigenic role of EPS8 and its potential as a therapeutic target. The EPS8 family of proteins, including EPS8-like (EPS8L) 1, EPS8L2 and EPS8L3, is a group of important regulators of behavior in mice and flies $(15,16)$. 
As the homolog of EPS8, EPS8L3 has been reported to be overexpressed in liver cancer tissues and cells. Furthermore, silencing and overexpression of EPS8L3 has been reported to reduce and increase the rate of proliferation, respectively; this was found to be dependent on the AKT signaling pathway, as an inhibition of AKT reverses the effect of EPS8L3 overexpression on proliferation in liver cancer (17). Little is known about the clinical relevance, significance to prognosis and potential regulatory effect on invasiveness and trans-migration of EPS8L3 in liver cancer. Therefore, the aim of the present study was to determine the potential function of EPS8L3 in liver cancer development by determining EPS8L 3 expression in liver cancer cells, and the effects of EPS8L3 knockdown on liver cancer cell proliferation and migration.

\section{Materials and methods}

Online database data retrieval. EPS8L3 expression data from liver cancer and non-tumor liver tissues were obtained from the Oncomine database (https://www.oncomine. org/resource/login.html). The clinical data of 338 patients with liver cancer were obtained from The Cancer Genome Atlas (TCGA) database (https://cancergenome.nih.gov/; Table I). The present study is in accordance with the publication guidelines provided by Oncomine and TCGA. In order to analyze the role of EPS8L3 in the progression of liver cancer, all patients with liver cancer were divided into EPS8L3 high $(\mathrm{n}=169)$ or low $(\mathrm{n}=169)$ expressing groups, according to the median value.

Cell culture and transfection. The normal human liver cell line HL-7702, and the liver cancer cell lines HepG2 and HCCLM3 were purchased from the Type Culture Collection of the Chinese Academy of Sciences. All cell lines were verified using short tandem repeats profiling. The cells were cultured in DMEM (Invitrogen; Thermo Fisher Scientific, Inc.) supplemented with 10\% FBS (Gibco; Thermo Fisher Scientific, Inc.), $100 \mathrm{U} / \mathrm{ml}$ penicillin and $0.1 \mathrm{mg} / \mathrm{ml}$ streptomycin at $37^{\circ} \mathrm{C}$ with $5 \% \mathrm{CO}_{2}$. During the logarithmic growth period, cells were collected and digested with $0.25 \%$ trypsin for $5 \mathrm{~min}$ at $37^{\circ} \mathrm{C}$ to obtain a single cell suspension. For RNA interference, $5 \times 10^{5}$ cells were seeded into a 24 -well plate the day before transfection. The following day, transfection of $100 \mathrm{nM}$ small interfering RNA (siRNA) into liver cancer cells was performed using Lipofectamine ${ }^{\circledR} 2000$ (Invitrogen; Thermo Fisher Scientific, Inc.), according to the manufacturer's instructions. siRNAs were synthesized by Shanghai GenePharma Co, Ltd. The sequences of the siRNAs were as follows: si-EPS8L3 1, 5'-AAUUCUCGGGGCUCUAAUGGG-3'; si-EPS8L3 1, 5'-UUUUACAAGCUUGAAGAUGCU-3'; si-con, 5'-UUC UCCGAACGUGUCACGU-3'. The expression of EPS8L3 at the mRNA and protein levels was determined $48 \mathrm{~h}$ after transfection using reverse transcription-quantitative (RT-q)PCR and western blotting. The siRNA whose silencing efficiency was the greatest was used in the subsequent experiments.

$R N A$ extraction and RT-qPCR. Total RNA was extracted from cells using TRIzol (Invitrogen; Thermo Fisher Scientific, Inc.), according to the manufacturer's protocol. Complementary DNA (cDNA) was synthesized at $37^{\circ} \mathrm{C}$ for $15 \mathrm{~min}$ and $85^{\circ} \mathrm{C}$ for $5 \mathrm{sec}$ using PrimeScript ${ }^{\mathrm{TM}} \mathrm{RT}$ reagent kit with gDNA Eraser (Takara
Table I. Association between the expression of EPS8L3 and clinicopathological features in 338 patients with liver cancer.

\begin{tabular}{|c|c|c|c|}
\hline \multirow[b]{2}{*}{ Characteristics } & \multicolumn{2}{|c|}{ Expression of EPS8L3 } & \multirow[b]{2}{*}{ P-value } \\
\hline & Low & High & \\
\hline Age & & & 0.383 \\
\hline$<60$ & 75 & 83 & \\
\hline$\geq 60$ & 94 & 86 & \\
\hline Sex & & & 0.198 \\
\hline Female & 48 & 59 & \\
\hline Male & 121 & 110 & \\
\hline Grade & & & 0.024 \\
\hline $\mathrm{G} 1+\mathrm{G} 2$ & 116 & 96 & \\
\hline G3 & 53 & 73 & \\
\hline Clinical stage & & & 0.137 \\
\hline $\mathrm{I}+\mathrm{II}$ & 131 & 119 & \\
\hline $\mathrm{III}+\mathrm{IV}$ & 38 & 50 & \\
\hline Tumor stage & & & 0.103 \\
\hline $\mathrm{T} 1+\mathrm{T} 2$ & 133 & 120 & \\
\hline $\mathrm{T} 3+\mathrm{T} 4$ & 36 & 49 & \\
\hline Node stage & & & 1.000 \\
\hline N0 & 167 & 167 & \\
\hline N1 & 2 & 2 & \\
\hline Metastasis stage & & & 0.562 \\
\hline M0 & 167 & 168 & \\
\hline M1 & 2 & 1 & \\
\hline Mortality & & & 0.011 \\
\hline Yes & 46 & 68 & \\
\hline No & 123 & 101 & \\
\hline
\end{tabular}

EPS8L3, epidermal growth factor receptor kinase substrate 8-like 3.

Bio, Inc.). RT-qPCR was performed using Power SYBR Green PCR Master Mix (Takara Bio, Inc.) on a 7300 Real-Time PCR system (Applied Biosystems; Thermo Fisher Scientific, Inc.) under the following thermocycling conditions: $94^{\circ} \mathrm{C}$ for $5 \mathrm{~min}$, followed by 40 cycles of $94^{\circ} \mathrm{C}$ for $30 \mathrm{sec}, 60^{\circ} \mathrm{C}$ for $45 \mathrm{sec}$ and $72^{\circ} \mathrm{C}$ for $30 \mathrm{sec}$. GAPDH was used as the endogenous control, and the primers were as follows: EPS8L 3 forward (F), 5'-CCT CATCAAAGGCAGGCTCT-3' and reverse (R), 5'-GCTCTG AGGTGAGGTTCTGG-3'; GAPDH F, 5'-GGAGCGAGATCC CTCCAAAAT-3' and R, 5'-GGCTGTTGTCATACTTCTCAT GG-3'. The relative expression of EPS8L3 was normalized to GAPDH using the $2^{-\Delta \Delta C q}$ method (18). Each experiment was performed in triplicate.

Western blot analysis. Cells were harvested $48 \mathrm{~h}$ following transfection and lysed in RIPA buffer (Beyotime Institute of Biotechnology) supplemented with protease inhibitor (Thermo Fisher Scientific, Inc.). After measuring protein concentrations using a bicinchoninic protein assay, proteins $(20 \mu \mathrm{g})$ were separated on 10-12\% SDS-PAGE gels and then transferred onto PVDF membranes. The membranes were blocked with 

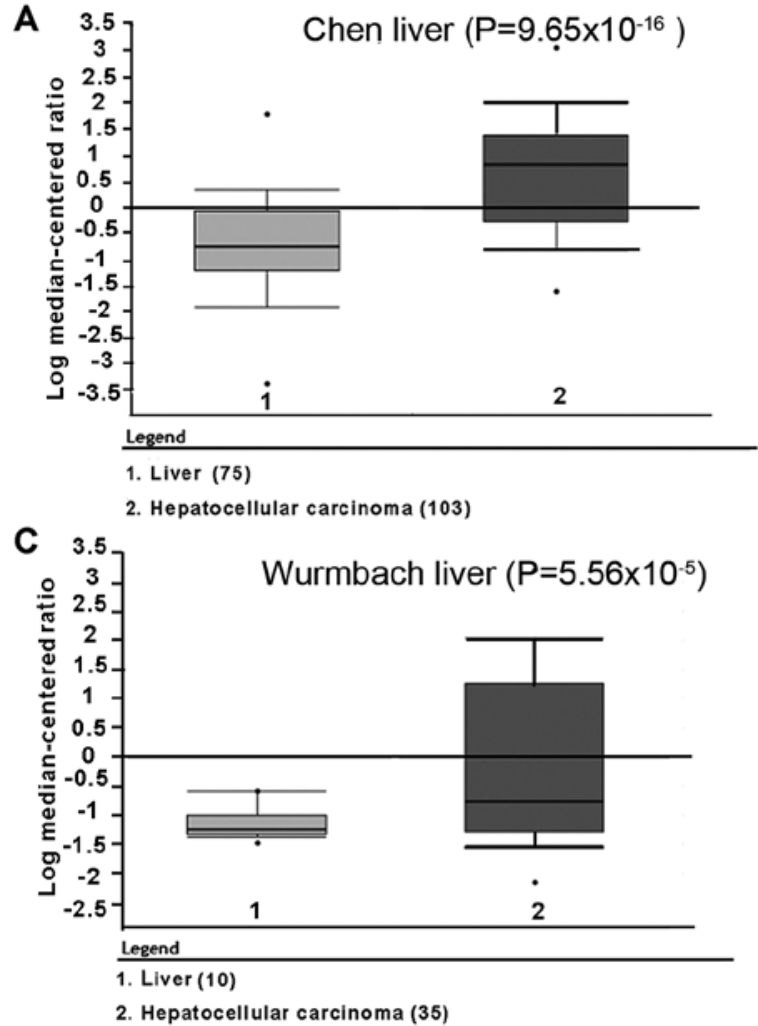

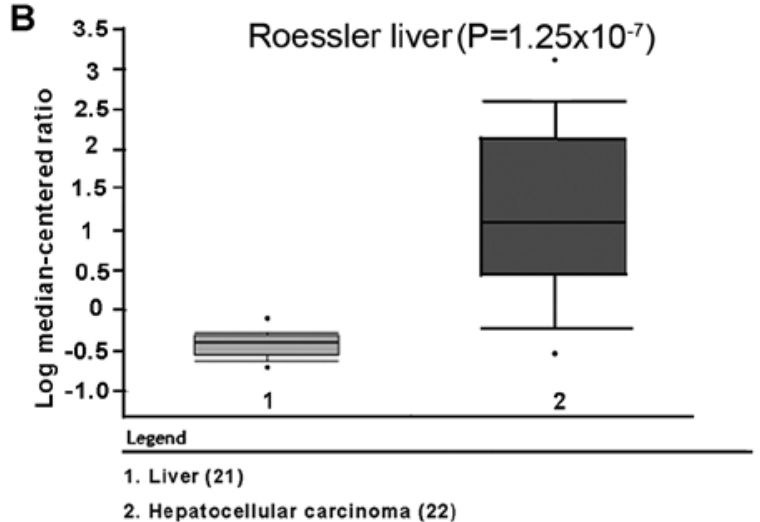

D

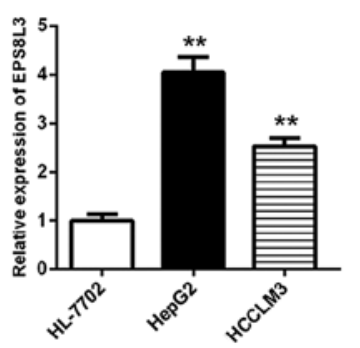

Figure 1. EPS8L3 expression in liver cancer tissues and cell lines. (A-C) Analysis of EPS8L3 expression in liver cancer tissues from data obtained from the Oncomine database. EPS8L3 was significantly upregulated in liver cancer tissues compared with normal liver samples. (D) EPS8L3 was found to be overexpressed in liver cancer cell lines (HepG2 and HCCLM3) compared with the normal liver cell line HL-7702. * P<0.01 vs. HL-7702. EPS8L3, epidermal growth factor receptor kinase substrate 8-like 3.

$5 \%$ skimmed milk for $1 \mathrm{~h}$ at room temperature, followed by incubation with primary antibodies, including EPS8L3 (1:1,000; cat. no. PA5-49855; Thermo Fisher Scientific, Inc.), phosphorylated (p)-PI3K (1:1,000; cat. no. 17366; Cell Signaling Technology, Inc.), PI3K (1:1,000; cat. no. 429; Cell Signaling Technology, Inc.), p-AKT (1:1,000; cat no. 9271, Cell Signaling Technology, Inc.), AKT (1:1,000; cat. no. 9272, Cell Signaling Technology, Inc.) and GAPDH (1:5,000; cat. no. $60004-1-\mathrm{Ig}$, ProteinTech Group, Inc.) at $4^{\circ} \mathrm{C}$ overnight. Next, the membranes were washed with $0.05 \%$ TBS-Tween 20 for $30 \mathrm{~min}$ and incubated with anti-rabbit/mouse horseradish peroxidase-conjugated secondary antibody $(1: 5,000$; cat nos. SA00001-2 and SA00001-1; ProteinTech Group, Inc) for $1 \mathrm{~h}$ at room temperature. The blots were visualized using a Hypersensitive ECL chemiluminescence detection kit (ProteinTech Group, Inc). Signals were analyzed using Quantity One version 4.6 (Bio-Rad Laboratories, Inc,). The relative expression of each protein was normalized to GAPDH.

Cell Counting Kit-8(CCK-8) assay. The effect of EPS8L 3 on cell viability was determined using a CCK-8 assay. Cell suspensions were seeded into 96-well plates at density of $1 \times 10^{3}$ cells/well and cultured for $24,48,72$ or $96 \mathrm{~h}$ in a $\mathrm{CO}_{2}$ incubator at $37^{\circ} \mathrm{C}$. CCK-8 solution (10 $\mu \mathrm{l} /$ well) was added and the optical density was measured at $450 \mathrm{~nm}$ after incubation at $37^{\circ} \mathrm{C}$ for $1.5 \mathrm{~h}$.

Wound healing assay. The migration of cells was assessed using wound healing assays. Cells, at a density of $1 \times 10^{5} /$ well,

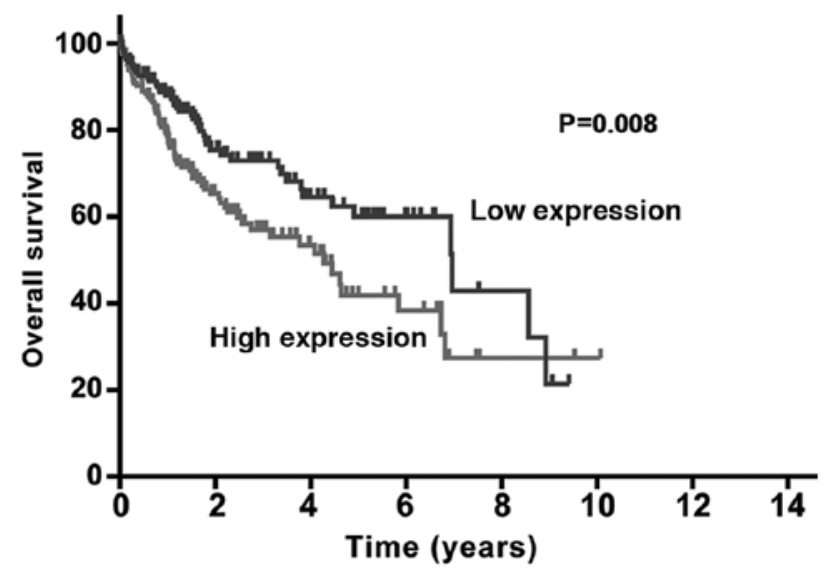

Figure 2. Survival analysis of patients with liver cancer expressing high or low levels of EPS8L3 using the Kaplan-Meier method. Patients with high EPS8L3 expression exhibited a lower survival rate than those with low EPS8L3 expression (Log rank test, $\mathrm{P}=0.008$ ). EPS8L3, epidermal growth factor receptor kinase substrate 8-like 3 .

were seeded into 6-well plates and grown to $80 \%$ confluency. The scratch test was performed after $24 \mathrm{~h}$. Wounds were scratched in each well using a $10-\mu l$ pipette tip. After washing with PBS to remove cellular debris, the cells were cultured in medium without FBS. Wound closure was monitored at 0 and $24 \mathrm{~h}$, and images were captured at x100 magnification using an inverted light microscope equipped with a Nikon camera (Nikon Corporation). 
Table II. Univariate and multivariate analyses of factors associated with survival.

\begin{tabular}{|c|c|c|c|c|c|c|}
\hline \multirow[b]{2}{*}{ Variables } & \multicolumn{3}{|c|}{ Univariate analysis } & \multicolumn{3}{|c|}{ Multivariate analysis } \\
\hline & P-value & HR & $95 \% \mathrm{CI}$ & P-value & HR & $95 \% \mathrm{CI}$ \\
\hline EPS8L3 expression, high/low & $0.009^{\mathrm{a}}$ & 1.654 & $1.136-2.406$ & 0.017 & 1.580 & $1.085-2.301$ \\
\hline Clinical stage, I + II/III + IV & $0.000^{\mathrm{a}}$ & 2.410 & $1.659-3.500$ & & & \\
\hline Tumor stage, $\mathrm{T} 1+\mathrm{T} 2 / \mathrm{T} 3+\mathrm{T} 4$ & $0.000^{\mathrm{a}}$ & 2.429 & $1.671-3.532$ & & & \\
\hline Metastasis stage, M0/M1 & $0.023^{\mathrm{a}}$ & 3.797 & $1.201-12.004$ & & & \\
\hline Node stage, $\mathrm{N} 0 / \mathrm{N} 1+\mathrm{N} 2+\mathrm{N} 3$ & 0.346 & 1.963 & $0.483-7.974$ & & & \\
\hline Age,$<60 / \geq 60$ & 0.217 & 1.264 & $0.871-1.835$ & & & \\
\hline Sex, female/male & 0.292 & 0.815 & $0.558-1.192$ & & & \\
\hline Grade, $\mathrm{G} 1+\mathrm{G} 2 / \mathrm{G} 3$ & 0.423 & 1.166 & $0.801-1.697$ & & & \\
\hline
\end{tabular}

EPS8L3, epidermal growth factor receptor kinase substrate 8-like 3; HR, hazard ratio; CI, confidence interval.

Statistical analysis. Statistical analyses were performed using SPSS 22.0 (IBM Corp.) and GraphPad Prism 7.0 (GraphPad Software, Inc.). All data were presented as the mean \pm standard deviation. Associations between EPS8L3 expression and clinical pathological parameters were analyzed using the $\chi^{2}$ test. Differences between multiple groups were analyzed using ANOVA followed by Tukey's post hoc test. Survival analysis was performed using the Kaplan-Meier method with a log-rank test. Univariate and multivariate analyses were performed using the Cox proportional hazards model to assess prognostic factors. $\mathrm{P}<0.05$ was considered to indicate a statistically significant difference.

\section{Results}

EPS8L3 is upregulated in human liver cancer tissues and cell lines. According to data in the Oncomine database, the expression of EPS8L3 in liver cancer tissues was significantly upregulated compared with normal liver samples $\left(\mathrm{P}=9.65 \times 10^{-16}\right.$ for Chen liver, $\mathrm{P}=1.25 \times 10^{-7}$ for Roessler liver and $\mathrm{P}=5.56 \times 10^{-5}$ for Wurmbach liver patient datasets; Fig. 1A-C). To further investigate the expression profile of EPS8L3, the mRNA expression levels of EPS8L3 were determined in two liver cancer cell lines (HepG2 and HCCLM3) and an immortalized human liver cell line (HL-7702). Consistent with the aforementioned findings in liver cancer tissue samples, the data revealed that the expression levels of EPS8L3 were significantly increased in liver cancer cell lines compared with in the normal liver cell line $(\mathrm{P}<0.01$; Fig. 1D). Collectively, the results suggested that EPS8L3 expression was increased in liver cancer, indicating that it may play an oncogenic role in the development of liver cancer.

Association between EPS8L3 expression, clinicopathological features and survival. As presented in Table I, high EPS8L3 expression was associated with high grade $(\mathrm{P}=0.024)$ and mortality $(\mathrm{P}=0.011)$; however, there was no significant association between EPS8L3 expression and other clinicopathologic parameters, including age, sex, clinical stage, tumor stage, node stage and metastasis stage $(\mathrm{P}>0.05)$.

Survival analysis using the Kaplan-Meier method revealed that patients with liver cancer who exhibited high levels of
EPS8L3 expression had a shorter survival time compared with those with low levels of EPS8L3 expression $(\mathrm{P}=0.008$; Fig. 2). Furthermore, a Cox proportional hazards regression model was used for univariate and multivariate analyses. In univariate analysis, several prognostic factors, including EPS8L3 expression $(\mathrm{P}=0.009)$, clinical stage $(\mathrm{P}<0.001)$, tumor stage $(\mathrm{P}<0.001)$ and metastasis stage $(\mathrm{P}=0.023)$ were identified (Table II). Multivariate analyses revealed that EPS8L3 expression (hazard ratio=1.58; 95\% confidence interval, 1.085-2.301; $\mathrm{P}=0.017$ ) could be independent predictor of overall survival (OS).

EPS8L3 knockdown inhibits cell proliferation and migration. After knocking down EPS8L3 expression in HepG2 cells using siRNA, the suppressive effects of the siRNAs were determined at $72 \mathrm{~h}$ using RT-qPCR and western blot analysis. As presented in Fig. 3A and B, EPS8L3 expression was inhibited significantly following siRNA transfection. EPS8L3 expression was significantly lower following EPS8L3 siRNA-1 transfection compared with EPS8L3 siRNA-2 transfection at the mRNA and protein levels $(\mathrm{P}<0.01)$. Therefore, si-EPS8L3-1, which achieved a $>90 \%$ reduction in EPS8L3 expression, was selected for use in the subsequent experiments. A CCK-8 assay revealed that EPS8L3 silencing significantly suppressed the rate of proliferation of the HepG2 cell line at 48, 72 and $96 \mathrm{~h}(\mathrm{P}<0.01$; Fig. 3C). Wound healing assays demonstrated that EPS8L3 knockdown induced a significant reduction in HepG2 cell migration, as indicated by the greater distance between the two wound fronts following EPS8L3 depletion compared with the control siRNA ( $\mathrm{P}<0.01$; Fig. 3D). In summary, these results indicated that the decreased expression of EPS8L3 inhibited the proliferation and migration of liver cancer cells.

Effects of EPS8L3 on the PI3K/AKT signaling pathway in liver cancer cells. Previous studies have reported that the PI3K/AKT signaling pathway plays an important role in the cell survival $(19,20)$; thus, the expression and phosphorylation of PI3K and AKT was evaluated to further investigate the potential role of EPS8L3 in liver cancer. It was observed that the knockdown of EPS8L3 significantly reduced the levels of 

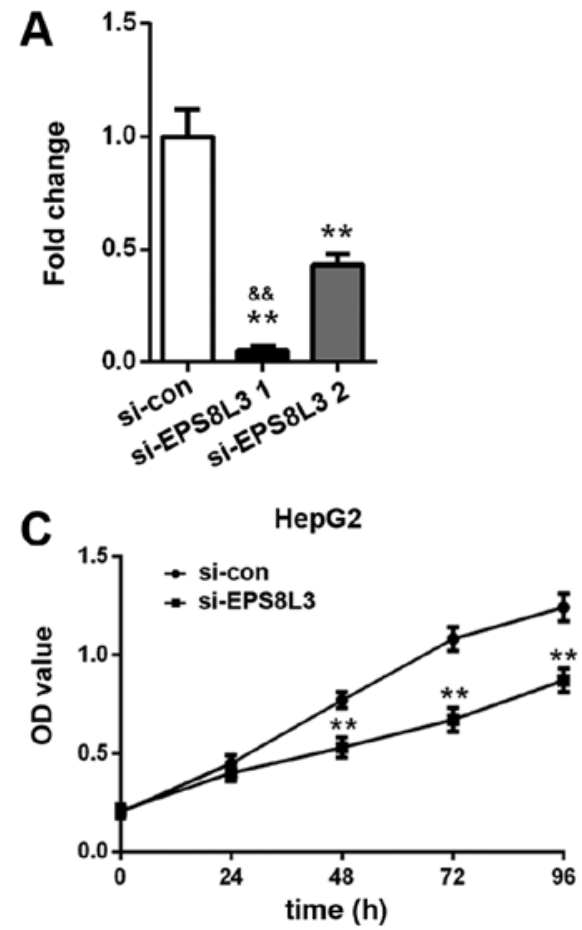
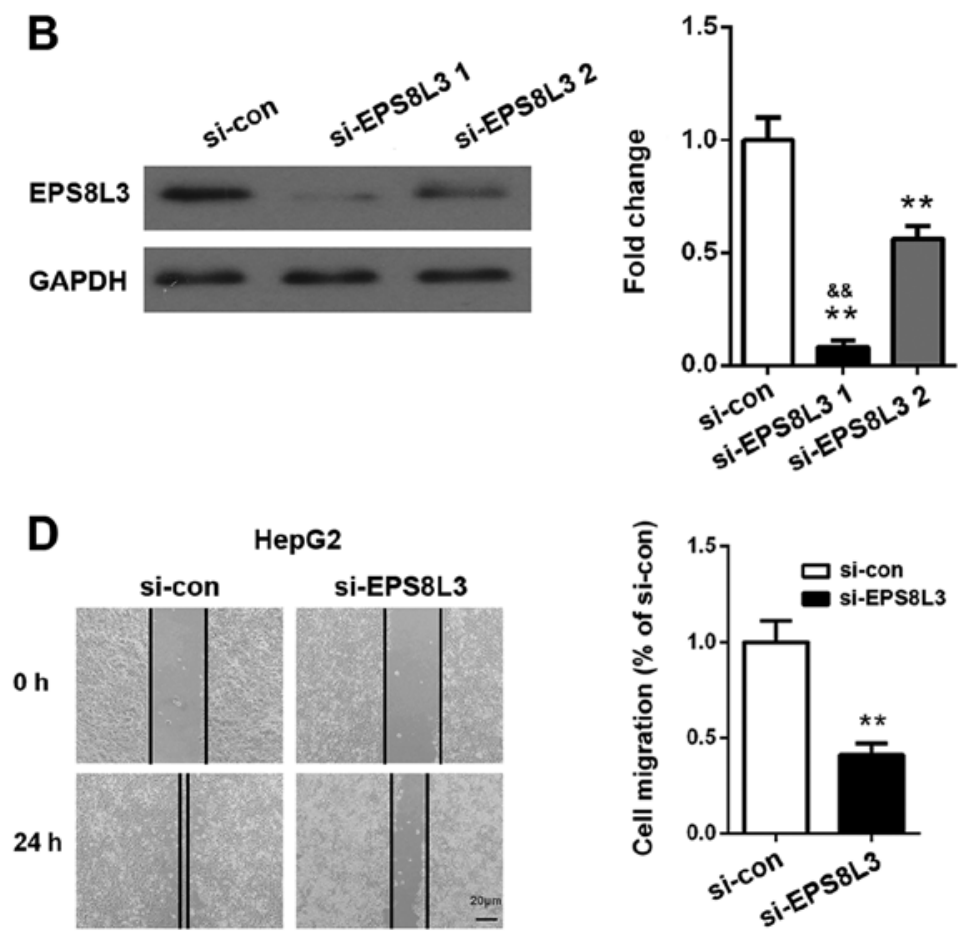

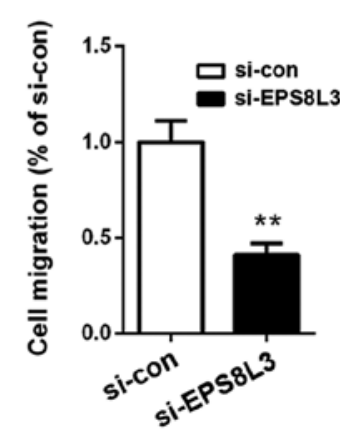

Figure 3. Functional alteration of liver cancer cells following EPS8L3 knockdown. EPS8L3 expression was significantly reduced using si-EPS8L3 1 and si-EPS8L3 2 as determined via (A) reverse transcription-quantitative PCR and (B) western blot analysis. Knockdown of EPS8L3 inhibited (C) cell proliferation and (D) migration. ${ }^{* *} \mathrm{P}<0.01$ vs. si-con, ${ }^{\& \&} \mathrm{P}<0.01$ vs. si-EPS8L3-2. EPS8L3, epidermal growth factor receptor kinase substrate 8-like 3; si, small interfering RNA; con, control; OD, optical density.
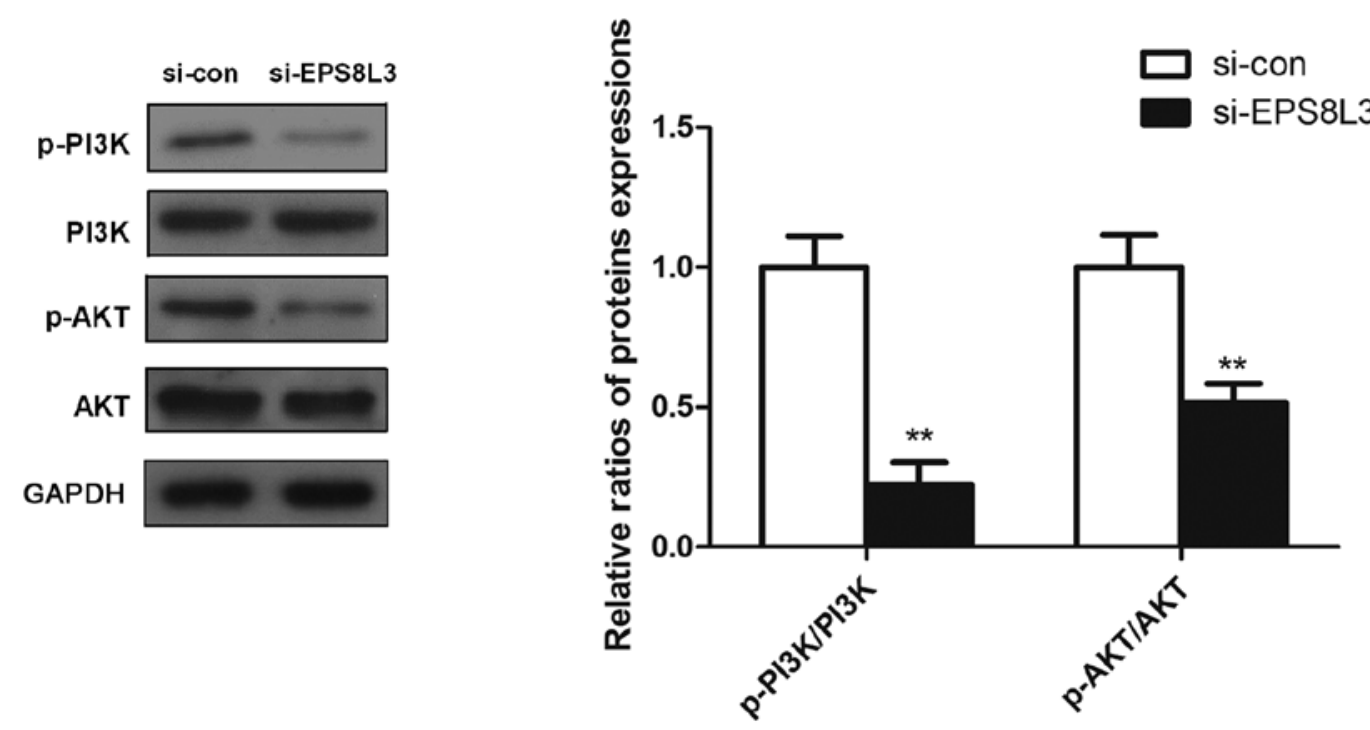

Figure 4. Effects of EPS8L3 knockdown on PI3K and AKT expression and phosphorylation in HepG2 cells. The ratios of p-PI3K/PI3K and p-AKT/AKT in cells in which EPS8L3 was silenced were significantly reduced compared with si-con. ${ }^{* *} \mathrm{P}<0.01 \mathrm{vs}$. si-con. EPS8L3, epidermal growth factor receptor kinase substrate 8-like 3; si, small interfering RNA; con, control; p-, phosphorylated.

p-PI3K and p-AKT in the HepG2 cell line, as indicated by the ratio of p-PI3K/PI3K and p-AKT/AKT (Fig. 4; P<0.01).

\section{Discussion}

EPS8 serves an important role in regulating the development and progression of a number of human tumors $(21,22)$; however, the clinical relevance, significance to prognosis and potential regulatory effect of EPS8L3 in liver cancer is not fully understood. In the present study, it was observed that EPS8L3 expression was significantly increased in liver cancer cell lines, which was consistent with the results from liver cancer tissues according to data obtained from the Oncomine database. In addition, the depletion of EPS8 significantly inhibited liver cancer cell proliferation and migration. Previous studies indicated that EPS8 was overexpressed in various solid tumors, including breast cancer (23), gliomas (24), squamous carcinoma (25) and ovarian cancer (26). Moreover, EPS8 is 
an important regulator of multiple biological functions in tumor cells. It has been recently been reported that EPS8L3 expression was significantly elevated in liver cancer tissues and cell lines, and that EPS8L3 silencing reduced the proliferation of liver cancer cells (16). The present study that found a high-level of EPS8L3 was predictive of a poor prognosis and identified EPS8L3 as an independent prognostic indicator in patients with liver cancer. The silencing of EPS8L3 reduced liver cancer cell proliferation, these data demonstrated that EPS8L3 acts as a promotor of liver cancer progression.

EPS8 has been identified as an oncogene (27), and Chen et al (28) reported that the upregulation of EPS8 expression was associated with shorter OS and disease-free survival in cervical cancer. Furthermore, He et al (21) revealed that patients with high EPS8 expression exhibited shorter event-free survival, and that EPS8 may be a valuable clinical biomarker for patients with acute lymphoblastic leukemia. These previous studies demonstrated the clinical significance of EPS8; thus, the present study further explored the potential value of EPS8L3 using data obtained from TCGA database for 338 patients with liver cancer. The results of the present study revealed that high EPS8L3 expression significantly associated with aggressive clinicopathological features, including higher tumor grade and mortality rate, which further suggested an oncogenic role for EPS8L3 in the development of liver cancer. Furthermore, survival analysis suggested that patients with liver cancer who had a high level of EPS8L3 expression had a significantly lower survival rate than those with a low EPS8L3 expression level. Therefore, EPS8L3 may be an independent predictor of prognosis. To the best of our knowledge, the present study is the first report to reveal the prognostic value of EPS8L3 for patients with liver cancer.

An increasing volume of evidence has shown that the abnormal activation of the PI3K/AKT signaling pathway is involved in the progression of a variety of solid tumors by regulating proliferation, differentiation, apoptosis and survival, including in liver cancer (29-33). EPS8 has been reported to be a signaling molecule involved in the regulation of the PI3K/AKT signaling pathway $(34,35)$. Additionally, Zeng et al (17) revealed that an AKT inhibitor suppressed the effects of EPS8L3 on the proliferation of EPS8L3-overexpressing cells, suggesting that EPS8L3 may promote proliferation by hyperactivating the AKT signaling pathway. Consistent with previous evidence that EPS8 knockdown inactivated the PI3K/AKT signaling pathway, the present study revealed that EPS8L3 depletion significantly reduced the levels of phosphorylated PI3K and AKT in liver cancer cells, indicating that EPS8L3 serves an important role in tumor development.

Collectively, the present study found that EPS8L3 expression was upregulated in liver cancer tissues and cell lines, and was associated with aggressive clinicopathological characteristics, including a higher tumor grade, higher mortality rate and poor prognosis. Moreover, EPS8L3 inhibited liver cancer cell proliferation and migration by regulating the PI3K/AKT signaling pathway. Thus, the results of the present study indicated that EPS8L3 could act as an oncogene in liver cancer and be a novel prognostic biomarker for patients with liver cancer. However, to further verify the findings of the present study, western blot analysis or immunohistochemistry is required to examine EPS8L3 expression in clinical specimens.

\section{Acknowledgements}

Not applicable.

\section{Funding}

No funding was received.

\section{Availability of material and data}

The datasets used and/or analyzed during the current study are available from the corresponding author on reasonable request.

\section{Authors' contributions}

GYC, PL and TH conceived and designed the study. PL, TH, HSW, YT and YM performed the experiments. XDW and YSX analyzed the data, revised the figures and drafted the manuscript. All authors read and approved the manuscript.

\section{Ethics approval and consent to participate}

Not applicable.

\section{Patient consent for publication}

Not applicable.

\section{Competing interests}

The authors declare that they have no competing interests.

\section{References}

1. Bray F, Ferlay J, Soerjomataram I, Siegel RL, Torre LA and Jemal A: Global cancer statistics 2018: GLOBOCAN estimates of incidence and mortality worldwide for 36 cancers in 185 countries. CA Cancer J Clin 68: 394-424, 2018.

2. Wu M, Liu Z, Zhang A and Li N: Identification of key genes and pathways in hepatocellular carcinoma: A preliminary bioinformatics analysis. Medicine (Baltimore) 98: e14287, 2019.

3. Haines K, Sarabia SF, Alvarez KR, Tomlinson G, Vasudevan SA, Heczey AA, Roy A, Finegold MJ, Parsons DW, Plon SE and López-Terrada D: Characterization of pediatric hepatocellular carcinoma reveals genomic heterogeneity and diverse signaling pathway activation. Pediatr Blood Cancer 66: e27745, 2019.

4. Wu M, Liu Z, Li X, Zhang A, Lin D and Li N: Analysis of potential key genes in very early hepatocellular carcinoma. World J Surg Oncol 17: 77, 2019.

5. Fu J and Wang H: Precision diagnosis and treatment of liver cancer in China. Cancer Lett 412: 283-288, 2018.

6. Della Corte C, Triolo M, Iavarone M and Sangiovanni A: Early diagnosis of liver cancer: An appraisal of international recommendations and future perspectives. Liver Int 36: 166-176, 2016.

7. Maluccio $\mathrm{M}$ and Covey $\mathrm{A}$ : Recent progress in understanding, diagnosing, and treating hepatocellular carcinoma. CA Cancer J Clin 62: 394-399, 2012.

8. El-Serag HB and Rudolph KL: Hepatocellular carcinoma: Epidemiology and molecular carcinogenesis. Gastroenterology 132: 2557-2576, 2007.

9. Yeudall A and Patel V: EPS8 signaling as a therapeutic target in oral cancer. Oral Dis 24: 128-131, 2018.

10. Ohshima K, Hatakeyama K, Kanto K, Ide T, Watanabe Y, Moromizato S, Wakabayashi-Nakao K, Sakura N, Yamaguchi K and Mochizuki T: Comparative proteomic analysis identifies exosomal Eps8 protein as a potential metastatic biomarker for pancreatic cancer. Oncol Rep 41: 1019-1034, 2019. 
11. Wen Q, Jiao X, Kuang F, Hou B, Zhu Y, Guo W, Sun G, Ba Y, Yu D, Wang D, et al: FoxO3a inhibiting expression of EPS8 to prevent progression of NSCLC: A new negative loop of EGFR signaling. EBioMedicine 40: 198-209, 2019.

12. Nasri E, Wiesen LB, Knapik JA and Fredenburg KM: Eps8 expression is significantly lower in $\mathrm{p}^{+} 6^{+}$head and neck squamous cell carcinomas (HNSCCs) compared with p16 HNSCCs. Hum Pathol 72: 45-51, 2018.

13. Wang Q and Yong L: Eps8, a therapeutic potential target for cancer. Hum Pathol 82: 300-301, 2018.

14. Chen Y, Xie X, Wu A, Wang L, Hu Y, Zhang H and Li Y: A synthetic cell-penetrating peptide derived from nuclear localization signal of EPS8 exerts anticancer activity against acute myeloid leukemia. J Exp Clin Cancer Res 37: 12, 2018.

15. Offenhäuser N, Castelletti D, Mapelli L, Soppo BE, Regondi MC Rossi P, D'Angelo E, Frassoni C, Amadeo A, Tocchetti A, et al: Increased ethanol resistance and consumption in Eps8 knockout mice correlates with altered actin dynamics. Cell 127: 213-226, 2006.

16. Tocchetti A, Confalonieri S, Scita G, Di Fiore PP and Betsholtz C: In silico analysis of the EPS8 gene family: Genomic organization, expression profile, and protein structure. Genomics 81 : 234-244, 2003.

17. Zeng CX, Tang LY, Xie CY, Li FX, Zhao JY, Jiang N, Tong Z, Fu SB, Wen FJ and Feng WS: Overexpression of EPS8L3 promotes cell proliferation by inhibiting the transactivity of FOXO1 in HCC. Neoplasma 65: 701-707, 2018.

18. Livak KJ and Schmittgen TD: Analysis of relative gene expression data using real-time quantitative PCR and the 2(-Delta Delta C(T)) method. Methods 25: 402-408, 2001.

19. Chen $\mathrm{H}, \mathrm{Li} \mathrm{H}$ and Chen Q: INPP4B reverses docetaxel resistance and epithelial-to-mesenchymal transition via the PI3K/Akt signaling pathway in prostate cancer. Biochem Biophys Res Commun 477: 467-472, 2016.

20. Sheng J, Shen L, Sun L, Zhang X, Cui R and Wang L: Inhibition of PI3K/mTOR increased the sensitivity of hepatocellular carcinoma cells to cisplatin via interference with mitochondrial-lysosomal crosstalk. Cell Prolif 52: e12609, 2019.

21. He YZ, Liang Z, Wu MR, Wen Q, Deng L, Song CY, Wu BY, Tu SF, Huang R and Li YH: Overexpression of EPS8 is associated with poor prognosis in patients with acute lymphoblastic leukemia. Leuk Res 39: 575-581, 2015.

22. Li M, Yang J, Zhang L, Tu S, Zhou X, Tan Z, Zhou W, He Y and Li Y: A low-molecular-weight compound exerts anticancer activity against breast and lung cancers by disrupting EGFR/Eps8 complex formation. J Exp Clin Cancer Res 38: 211, 2019.

23. Chen C, Liang Z, Huang W, Li X, Zhou F, Hu X, Han M, Ding X and Xiang S: Eps8 regulates cellular proliferation and migration of breast cancer. Int J Oncol 46: 205-214, 2015.
24. Ding X, Zhou F, Wang F, Yang Z, Zhou C, Zhou J, Zhang B, Yang J, Wang G, Wei Z, et al: Eps8 promotes cellular growth of human malignant gliomas. Oncol Rep 29: 697-703, 2013.

25. Schoenherr C, Serrels B, Proby C, Cunningham DL, Findlay JE, Baillie GS, Heath JK and Frame MC: Eps8 controls Src- and FAK-dependent phenotypes in squamous carcinoma cells. J Cell Sci 127: 5303-5316, 2014.

26. Chen $\mathrm{H}, \mathrm{Wu} X, \mathrm{Pan} \mathrm{ZK}$ and Huang S: Integrity of SOS1/EPS8/ABI1 tri-complex determines ovarian cancer metastasis. Cancer Res 70: 9979-9990, 2010.

27. Li YH, Xue TY, He YZ and Du JW: Novel oncoprotein EPS8: A new target for anticancer therapy. Future Oncol 9: 1587-1594, 2013.

28. Chen YJ, Shen MR, Chen YJ, Maa MC and Leu TH: Eps8 decreases chemosensitivity and affects survival of cervical cancer patients. Mol Cancer Ther 7: 1376-1385, 2008.

29. Yu HY, Kim SO, Jin CY, Kim GY, Kim WJ, Yoo YH and Choi YH: $\beta$-lapachone-induced apoptosis of human gastric carcinoma AGS cells is caspase-dependent and regulated by the PI3K/Akt pathway. Biomol Ther (Seoul) 22: 184-192, 2014.

30. Fu YL, Zhang QH, Wang XW and He H: Antidiabetic drug metformin mitigates ovarian cancer SKOV3 cell growth by triggering G2/M cell cycle arrest and inhibition of m-TOR/PI3K/Akt signaling pathway. Eur Rev Med Pharmacol Sci 21: 1169-1175, 2017.

31. Paplomata E and O'Regan R: The PI3K/AKT/mTOR pathway in breast cancer: Targets, trials and biomarkers. Ther Adv Med Oncol 6: 154-166, 2014

32. Zhang H, Cao Y, Chen Y, Li G and Yu H: Apatinib promotes apoptosis of the SMMC-7721 hepatocellular carcinoma cell line via the PI3K/Akt pathway. Oncol Lett 15: 5739-5743, 2018.

33. Fu X, Liu M, Qu S, Ma J, Zhang Y, Shi T, Wen H, Yang Y, Wang S, Wang $\mathrm{J}$, et al: Exosomal microRNA-32-5p induces multidrug resistance in hepatocellular carcinoma via the PI3K/Akt pathway. J Exp Clin Cancer Res 37: 52, 2018.

34. Xu M, Shorts-Cary L, Knox AJ, Kleinsmidt-Demasters B, Lillehei $\mathrm{K}$ and Wierman ME: Epidermal growth factor receptor pathway substrate 8 is overexpressed in human pituitary tumors: Role in proliferation and survival. Endocrinology 150: 2064-2071, 2009.

35. Wang H, Patel V, Miyazaki H, Gutkind JS and Yeudall WA: Role for EPS8 in squamous carcinogenesis. Carcinogenesis 30: 165-174, 2009. 